\title{
La formulación del estilo mudéjar en el siglo del Romanticismo: una propuesta de estudio desde la literatura de viajes.
}

\author{
The formulation of the mudéjar style in the \\ century of Romanticism: a proposal of study \\ from the travel literature.
}

\author{
Pedro Victorio SALIDO LÓPEZ \\ Universidad de Castilla-la Mancha
}

Recibido: 09-I-2014 / Aceptado: 30-V-2014

Resumen: En 1859 José Amador de los Ríos pronunció su discurso de entrada a la Real Academia de Bellas Artes de San Fernando con el título "El estilo mudéjar en arquitectura". Bajo esta denominación se iban a incluir construcciones repartidas por todo el territorio español que participaban de las características propias de las corrientes artísticas cristianas y a su vez se veían influenciadas por el arte islámico desarrollado en al-Andalus entre el 711 y 1492 . Se iniciaba así uno de los debates historiográficos más polémicos de la Historia del Arte. Para algunos estudiosos el mudéjar se mostraba como un nuevo estilo representativo del arte español. En contra, otros especialistas consideraron que los edificios catalogados bajo la denominación de Amador de los Ríos no perdían la esencia del arte de su tiempo, llegando a defender que el "estilo mudéjar" no era más que un marcador de identidad nacional propio del siglo XIX. En este sentido, el trabajo que se desarrolla en las líneas siguientes presenta una reflexión en torno al debate generado sobre la legitimidad de usar el término acuñado por De los Ríos como categoría estilística. Para ello, me serviré de las descripciones que los viajeros extranjeros realizaron de los edificios toledanos colocados al amparo del estilo mudéjar, considerando que 1859 fue el año que marcó un antes y un después.

Palabras clave: Mudéjar, Estilo, Estética, Arte medieval, Literatura de viajes.

ABstract: In 1859 José Amador de los Ríos made his acceptance speech to the Real Academia de Bellas Artes de San Fernando entitled "El estilo mudéjar en arquitectura". This new stylistic category included buildings found in the Spanish territory that shared the characteristics common to the Christian, Romanesque or Gothic style, and also were influenced by the Islamic art developed in al-Andalus between 711 and 1492. The term of Amador de los Ríos became one of the most controversial historiographical debates of the History of Art. According to some researchers, the mudéjar was regarded as a new representative style of Spanish art. Other experts considered the buildings listed under the name mudéjar not to have lost the Romanesque and Gothic essence; even supporting the idea of the "mudéjar style" as a sign of national identity of the nineteenth century. In this sense, this article presents a reflection around this debate and the legitimacy of the use of the term mudéjar as a stylistic category. To do this, I will use buildings descriptions by foreign travelers classified as mudéjar, considering 1859 as the year which marked a turning point.

Key words: Mudéjar, Style, Aesthetic, Medieval art, Travel literature. 


\section{INTRODUCCIÓN}

Cuando nos enfrentamos al análisis y conocimiento del arte medieval es indispensable referirnos a la conceptualización y posible delimitación del uso dado al término mudéjar como categoría estilística. El hecho de que en 1859 José Amador de los Ríos defendiera la existencia de "un estilo mudéjar en arquitectura" permitió a muchos estudiosos aglutinar bajo una nueva categorización pequeños edificios construidos en la Edad Media en gran parte del territorio español en los que conviven elementos de la arquitectura cristiana y andalusí. Sin embargo, otros especialistas consideraron poco adecuada su formulación por el carácter étnico del término -mudéjar deriva de mudayyan y hace referencia a los musulmanes a quienes se les permitió seguir viviendo en territorio cristiano- y por la falta de elementos constructivos que permitieran hablar de una manera de construir independiente al arte de su tiempo. Estamos, pues, ante planteamientos opuestos que han supuesto el origen de uno de los problemas terminológicos más difíciles de resolver de la Historia del Arte.

Son muchas las fuentes que nos permiten aclarar, o en ocasiones alimentar, el debate derivado del uso de un término que alude al origen étnico de la mano de obra para definir un estilo artístico nacional que hace diferente la arquitectura española de la del resto de países europeos. En nuestro caso, y sin olvidar la problemática de los estilos y los estudios más formalistas, nos serviremos de las descripciones del patrimonio de Toledo realizadas por algunos viajeros con el objetivo de valorar hasta qué punto el "estilo mudéjar" fue considerado por la mirada de los extranjeros como una manera de construir diferente a la de la tradición cristiana occidental de la Edad Media. Concretamente, utilizaremos como guías de viaje el A handbook for travellers in Spain and readers at home del inglés Richard Ford ${ }^{1}$ y el Voyage

1 Las memorias del viaje a España de Richard Ford fueron publicadas por el editor John Murray en 1845 bajo el título $A$ handbook for travellers in Spain and en Espagne de los franceses Gustave Doré y Charles Davillier ${ }^{2}$. Estos dos textos son algunas de las fuentes aportadas por la literatura de viajes para conocer la realidad de España en el siglo XIX descrita por extranjeros. Si bien, mientras que Ford realizó su periplo por la Península algunos años antes de ese 1859 en el que Amador de los Ríos pronunció su discurso de entrada a la Real Academia de Bellas Artes de San Fernando, Davillier llegó a nuestro país en la década de los sesenta de ese siglo XIX y en las notas de su viaje ya dio noticia de "un estilo de arquitectura que se llama en España mudéjar"3.

\section{"EL ESTILO MUDÉJAR EN ARQUI- TECTURA" A DEBATE: UN BREVE RECORRIDO HISTORIOGRÁFICO}

Como señalábamos a modo de introducción, en 1859 José Amador de los Ríos

readers at home, obra de la que se hicieron numerosas ediciones en las décadas siguientes (R. FORD, $A$ handbook for travellers in Spain, 2 vols., $3^{\text {a }}$ ed., Londres, 1855). Este libro de viajes se ha traducido al español bajo el título Manual para viajeros en España y lectores en casa en diferentes volúmenes que atienden a las regiones españolas visitadas y descritas por este viajero inglés. Las impresiones que Ford tuvo a su paso por los territorios de la actual Castilla-La Mancha las podemos encontrar en R. FORD, Manual para viajeros por Castilla y lectores en casa, trad. de Jesús Pardo, vol. 2, Madrid, 1981.

2 El Voyage en Espagne de los franceses Gustave Doré y Charles Davillier fue publicado en la revista de viajes Le Tour du Monde entre 1862 y 1873. La parte correspondiente con las notas sobre Toledo apareció en el segundo número de 1868-G. DORÉ y CH.DAVILLIER, "Voyage en Espagne", Le Tour du Monde. Nouveau Journal des Voyages, no XVIII, 1868, 2º semestre, pp. 321352. Bibliotèque Nacionale de France, consultado el 10 de abril de 2014. URL: http://gallica.bnf.fr/ark:/12148/ bpt6k343936-, texto en francés de referencia para el desarrollo de este trabajo. En 1874 la Editorial Hachette reunió todas las entregas de la prestigiosa revista de viajes en un solo volumen, edición que publicó bajo el título L'Espagne y en la que el ilustrador Doré aparecía como autor secundario (CH. DAVILLIER y G. DORÉ, L'Espagne, París, 1874). La traducción al español del "Voyage en Espagne" de referencia para este trabajo ha sido la publicada por la Editorial Grech (G. DORÉ y CH. DAVILLIER, Viaje por España, 2 vols., Madrid, 1988).

${ }^{3}$ G. DORÉ y CH. DAVILLIER, Viaje por..., vol. 2, p. 138. 
utilizó el término "mudéjar" en su discurso de entrada a la Real Academia de Bellas Artes de San Fernando para referirse a una manifestación artística. De los Ríos defendía la existencia de un "singular estilo (...) propio y característico de la civilización española $[\ldots]^{\prime \prime}$. Su criterio, y el de todos sus partidarios, giraba en torno a la idea de incluir bajo el término mudéjar obras que contaban con elementos decorativos de origen andalusí, empleaban yeso, adobe o ladrillo en sus muros, madera en sus techumbres o sus artífices eran de origen musulmán.

La tesis de Amador de los Ríos iba a ser el caballo de batalla para todos los interesados en el estudio de los estilos de las artes, pues muchos de ellos no consideraron legítimo el uso del término "mudéjar" como categoría estilística ${ }^{5}$. En este sentido, muy pocos años después del discurso pronunciado por De los Ríos el profesor de sánscrito y arqueólogo Manuel de Assas consideró que desde el punto de vista formal la arquitectura "mudéjar" pertenecía al arte islámico ${ }^{6}$.

${ }^{4}$ Así se recoge en la edición de su discurso publicada en 1872, en la que añadió algunas notas al texto de 1859 (J. AMADOR DE LOS RÍOS, El estilo mudéjar en arquitectura, Madrid, 1872, p. 33).

${ }^{5}$ En este apartado del artículo se expondrán algunas de las opiniones vertidas en torno al arte mudéjar con la finalidad de dar a conocer al lector los aspectos más importantes de este debate historiográfico. Para ampliar la información al respecto, véanse algunos trabajos de enorme interés como el de G. BORRÁS, El arte mudéjar, Teruel, 1990, pp. 11-73, el de J. C. RUIZ SOUZA, “Le style mudéjar en architecture cent cinquante ans après", Perspective, 2009, 2, pp. 277-286 o el de A. URQUÍZAR HERRERA, "La caracterización política del concepto mudéjar en España durante el siglo XIX", Espacio, tiempo y forma, Serie VII, t. 22-23, 2009-2010, pp. 201-216.

${ }^{6} \mathrm{M}$. DE ASSAS Y EREÑO, “Nociones fisionómicohistóricas de la arquitectura en España. Monumentos de estilo mahometano desde el siglo VIII al siglo XVI", Semanario Pintoresco Español, no 45, 1857, p. 354. El artículo de Manuel de Assas se fechó en 1857, lo que generó un debate historiográfico en torno a la fecha de origen del término mudéjar aplicado a una manifestación artística. No obstante, está demostrado que el texto de Assas es posterior al discurso leído por Amador de Ríos en 1859 (G. BORRÁS, Op.cit., p. 16).
A partir de este momento fueron numerosas las opiniones que cuestionaban la posibilidad de otorgar el calificativo de "mudéjar" a una estética medieval en la que convivían formas islámicas y cristianas. Por ejemplo, Pedro de Madrazo publicó en 1888 un artículo en La Ilustración española y americana bajo el título "De los estilos en las artes". Madrazo se mostró crítico con el hecho de que José Amador de los Ríos utilizara un concepto que alude a la condición personal del artífice para definir un estilo, aconsejando "abandonar la peligrosa novedad de este vocablo" por no aludir a nada determinado y definido ${ }^{7}$. Además, consideró que la condición social de los mudéjares no fue una causa para que se alejaran del arte de su tiempo, señalando sobre la nueva categorización estilística:

“[...] y si lo que hoy damos en llamar mudéjar es árabe-bizantino con mezcla de románico, dígase así explícitamente; y si lo mudéjar es de estilo mauritano o moghrebita con rasgos románicos, o bizantinos, o góticos, señálese así también con los nombres que a tal compuesto respondan $[\ldots]^{\prime \prime}$.

Vicente Lampérez, arquitecto e historiador del arte español, también se interesó por acotar el arte mudéjar, "obra de moros, puestos al servicio de sus conquistadores $\mathrm{y}$, en muchos casos también, obra de estos aleccionados por aquellos ${ }^{\prime \prime}$. La indefinición de características formales de esta manera de construir ${ }^{10}$ le llevó a hablar de una "ar-

7 P. DE MADRAZO, "De los estilos en las artes", La Ilustración Española y Americana, t. XLIV, no ${ }^{\circ}$ 15, 1888, pp. 262-263. Hemeroteca digital de la BNE, consultado el 10 de octubre de 2013. URL: http://hemerotecadigital. bne.es/results.vm?q=parent\%3A0001066626\&s=840\&la ng=es

${ }^{8}$ Ibídem, p. 263.

${ }^{9}$ V. LAMPÉREZ Y ROMEA, Historia de la arquitectura cristiana española en la Edad Media, t. II, facs. de la ed. 1908-1909, Valladolid, 1999, p. 539.

${ }^{10}$ El propio Amador de los Ríos no acotó de manera clara las características del arte mudéjar, señalando en su discurso: "[...] permitidme que no me detenga a fijar menudamente sus peculiaridades y caracteres, cuando 
quitectura románica de ladrillo" que diferenciaba de la que se "conoce con el nombre de mudéjar"11. Esta propuesta de Lampérez no fue aceptada por el Marqués de Lozoya, pues según su criterio el estilo acuñado por Amador de los Ríos no debía designar una variedad del Románico por ser algo totalmente distinto ${ }^{12}$. De la misma manera, Borrás Gualis consideró algunos años después que en aquellos edificios medievales en los que se abandonó el sistema de trabajo en piedra para utilizar el ladrillo no se produjo un cambio de materiales, sino que una obra de planteamiento románico se convirtió en una obra mudéjar ${ }^{13}$.

Por otro lado, Vicente Lampérez propuso una clasificación de las obras mudéjares vinculada a los estilos de la arquitectura medieval cristiana. En este sentido, consideró la existencia de un "mudéjar-románico (siglos XI-XII)" y un "mudéjar-gótico" (siglos XIV, XV y aún el XVI) ${ }^{14}$. Esta propuesta no iba ser aceptada posteriormente por historiadores del arte como Joaquín Yarza Luaces $^{15}$, surgiendo la cuestión de hasta qué punto una categorización que supeditaba el mudéjar a dos de los grandes periodos de la historia del arte suponía reducir los aportes islámicos a la arquitectura medieval cristiana a lo puramente ornamental.

El Marqués de Lozoya también hizo alguna matización a la terminología acuñada por Amador de los Ríos. Lozoya habló de una "arquitectura morisca" en lugar de "mudéjar" -entre los ejemplos que presentó

a ninguno de vosotros pueden ser desconocidos" (J. AMADOR DE LOS RÍOS, Op. cit., p. 33).

${ }^{11}$ V. LAMPÉREZ Y ROMEA, Op. cit., t. I, pp. 699-701.

12. J. DE CONTRERAS, MARQUÉS DE LOZOYA, Historia del arte hispánico, t. II, Barcelona, 1934, p. 45.

13 G. BORRÁS GUALIS, El Islam. De Córdoba al mudéjar, vol. 3, Madrid, 2003, p. 195.

14 Añade, además, un "mudéjar latino-bizantino (siglos X y XI) y un mudéjar-plateresco (siglo XVI) (V. LAMPÉREZ Y ROMEA, Op. cit., t. II, p. 546).

${ }^{15} \mathrm{~J}$. YARZA LUACES, Arte y arquitectura en España: 500-1250, Madrid, 1981, pp. 311-313. de esta manera de construir en su Historia del arte hispánico incluyó algunos edificios toledanos-. Según su criterio, ambas palabras son sinónimas, pero la primera "tiene la ventaja de ser más castiza y expresiva"16. Evidentemente, esta aportación no vino a solucionar el debate etimológico generado por Amador de los Ríos por estar ante otro término con carácter étnico que se refería a una realidad artística -"morisco" como sustantivo hace referencia a los musulmanes convertidos al cristianismo-.

Entre los trabajos que han intentado definir de una manera clara y nítida el estilo acuñado por De los Ríos destacan también los de José María Azcárate. En su Arte gótico en España recogió las construcciones catalogadas como mudéjares en un capítulo titulado "arquitectura cristiana islamizada (mudéjar)"17. Su denominación surge de las características constructivas y decorativas de este tipo de edificios -"bien sean hechos por artistas musulmanes o cristianos", señala en lo que atañe a la mano de obra-, pues son numerosos los rasgos heredados de las formas hispanomusulmanas y puestos al servicio de la arquitectura cristiana medieval. Según Azcárate, la fusión de las culturas cristiana e islámica en territorio hispánico permitió el desarrollo de un estilo "verdaderamente nacional"18.

Por su parte, Borrás Gualis consideró que esta estética surge como una nueva realidad artística que es consecuencia de las condiciones de convivencia de culturas en la España medieval, una creación "genuinamente hispánica que no encaja en la historia del arte islámico ni en la del occidental, porque se haya justamente en la frontera de las culturas islámica y cristiana, eslabón de enlace entre la Cristiandad y el Islam"19.

${ }^{16}$ J. DE CONTRERAS, MARQUÉS DE LOZOYA, Op. cit., t. II, pp. 45-46.

${ }^{17}$ J. M. AZCÁRATE, Arte gótico en España, Madrid, 1990, pp. 71-107.

${ }^{18}$ Ibídem, p. 71.

${ }^{19}$ G. BORRÁS GUALIS, El Islam. De Córdoba..., p. 195. 
Mientras, otros historiadores del arte han valorado la caracterización política e ideológica del término acuñado por De los Ríos, pues consideran que los orígenes del arte mudéjar aparecen claramente relacionados con un marcador de la identidad nacional propio del siglo del Romanticismo. En este contexto, han surgido opiniones que consideran que ni las técnicas constructivas y materiales empleados para levantar las obras catalogadas como mudéjares, ni la supuesta convivencia de culturas en la España medieval -musulmanes, cristianos y judíos-, ni los artífices de este tipo de construcciones, en muchos casos no solo musulmanes, se pueden considerar como elementos determinantes para diferenciar esta arquitectura de su coetánea ${ }^{20}$.

Podrían ser algunos más los estudios, las aportaciones y las matizaciones hechas en torno al discurso de De los Ríos -Concepción Abad Castro ${ }^{21}$, Teresa Pérez Higuera ${ }^{22}$ María Elena Díez Jorge ${ }^{23}$, entre otras-, pero basta con estos ejemplos para demostrar la complejidad que ha supuesto para arquitectos e historiadores y teóricos del arte definir claramente las características del estilo mudéjar en arquitectura.

${ }^{20}$ J. C. RUIZ SOUZA, Estudios y reflexiones sobre la arquitectura de la Corona de Castilla y el Reino de Granada en el siglo XIV: creatividad y/o crisis, Madrid, 2000. ÍDEM, "Construcción y búsqueda de un estilo nacional. El estilo mudéjar ciento cincuenta años después", en J. A. GONZÁLEZ ALCANTUD (ed.), La invención del estilo hispano-magrebí: presente y futuros del pasado, Barcelona, 2010, pp. 177-199, o J. D. DODDS, M. R. MENOCAL y A. KRASNER BALBALE, The arts of intimacy. Christians, jews, and muslims in the making of castilian culture, New Haven \& London, 2008, p. 120.

${ }^{21}$ M. C. ABAD CASTRO, Arquitectura mudéjar toledana en el arzobispado de Toledo, 2 vols., Toledo, 1991.

${ }^{22}$ T. PÉREZ HIGUERA, "Los palacios mudéjares castellanos: los modelos islámicos y su interpretación", en M. C. LACARRA DUCAY (coord.), Arte mudéjar en Aragón, León, Castilla, Extremadura y Andalucía, Zaragoza, 2006, p. 183.

${ }^{23}$ M. E. DÍEZ JORGE, El arte mudéjar: expresión estética de una convivencia, Granada, 2001.
LA ESTÉTICA MUDÉJAR ANTES Y DESPUÉS DE 1859: DEL A HANDBOOK FOR TRAVELLERS IN SPAIN AND READERS AT HOME DE RICHARD FORD AL VOYAGE EN ESPAGNE DE GUSTAVE DORÉ Y CHARLES DAVILLIER $^{24}$

Cuando hablamos del "mudéjar" como manifestación artística, y tomando como referencia las descripciones de extranjeros que con espíritu romántico vinieron a España para "recrear su fantasía en los días de otra época imposible ya" ${ }^{25}$, surge la duda de cómo se vieron y valoraron estas construcciones medievales antes de que Amador de los Ríos pronunciara su discurso de entrada a la Real Academia de Bellas Artes de San Fernando. En este sentido, las siguientes páginas se dedicarán a analizar las descripciones recogidas en las memorias de viajeros del siglo del Romanticismo sobre los edificios medievales de Toledo catalogados como mudéjares, conscientes de que el año 1859 marcó un punto de inflexión. Esta elección se fundamenta en el hecho de que la actual capital castellano-manchega fue una de las ciudades de visita obligada para aquellos que en el siglo XIX cruzaron los Pirineos en busca algo nuevo y diferente a lo europeo, por lo que son numerosos los textos referidos a ella. Pero además, parte de los trabajos sobre arte medieval reivindican la existencia

24 El recorrido por el patrimonio medieval de Toledo descrito por estos viajeros extranjeros se apoyará en fotografías digitalizadas y publicadas on-line por el Archivo Municipal del Exmo. Ayuntamiento de Toledo -URL: http://www.aytotoledo.org/archivo/archivo.asp, consultado el 10 de junio de 2014- y por el Archivo de la imagen de la Junta de Comunidades de Castilla La Mancha -URL: http://clip.jccm.es/archivo_de_la_imagen/es/ micrositios/inicio.cmd, consultado el 10 de junio de 2014-. Atendiendo a los términos que regulan el uso y la reproducción de este tipo de material, a lo largo del trabajo se incluirán $u r l$ 's para consultar en Internet las imágenes de interés para el desarrollo del tema propuesto.

25 L. CERNUDA, Divagación sobre la Andalucía romántica, 1935, en D. HARRIS y L. MARISTANY (ed.), Prosa completa, Barcelona, 1975, p. 1280. 
de un foco "mudéjar toledano" ${ }^{26}$ por el papel que la antigua capital visigoda tuvo como foco creador y difusor de las características artísticas dadas a esta arquitectura ${ }^{27}$.

Como señalaba en páginas anteriores, el libro de viajes del que me serviré para conocer la manera en que los extranjeros describieron la arquitectura catalogada como mudéjar con anterioridad a 1859 es el $A$ handbook for travellers in Spain and readers at home del inglés Richard Ford, que llegó a España en 1830 y regresó a Inglaterra en 1833. Su paso por Toledo se orientó en la línea romántica de conocer una ciudad medieval "verdaderamente interesante (...) que nos aleja del presente" ${ }^{28}$. En este contexto decimonónico no está de más pensar que iglesias como la de Santiago del Arrabal debieron ser muy atractivas para la mirada de los viajeros extranjeros, pues historiadores y cronistas españoles interesados por dar a conocer el patrimonio nacional fuera de nuestras fronteras -caso del toledano Sixto Ramón Parro ${ }^{29}$ describieron la magnificencia de algunos de estos oratorios cristianos de barrio. A pesar de ello, en las memorias de Ford solo encontramos una breve alusión a este edificio en la que aconseja observar su "patio, pórtico

${ }^{26}$ M. GÓMEZ MORENO, Arte mudéjar toledano, Madrid, 1916, G. TÉLLEZ, "El estilo mudéjar toledano", Boletín de la Real Academia de Bellas Artes y Ciencias Históricas de Toledo, no 60, 1945-1946, pp. 65-106 o B. PAVÓN MALDONADO, Arte toledano: islámico y mudéjar. Madrid, 1973, entre otros.

27 Tras la reconquista de Toledo en 1085 se construyeron en toda la ciudad "veynte y seis iglesias" de barrio -muchas de ellas conservadas en la actualidad- que respondían a las características de esta arquitectura medieval y de las que dio noticia Luis Hurtado de Toledo en su Memorial de algunas cosas notables que tiene la ciudad de Toledo, texto de la segunda mitad del siglo XVI (L. HURTADO DE TOLEDO, Relaciones histórico-geográfico-estadísticas de los pueblos de España hechas por iniciativa de Felipe II: Reino de Toledo, III, ed. C. Viñas y R. Paz, Madrid, 1951, p. 485).

${ }^{28}$ R. FORD, Manual para viajeros por Castilla..., vol. 2, p. 78.

${ }^{29}$ S. RAMÓN PARRO, Toledo en la mano, vol. 2, facs. de la ed. de 1857, Toledo, 1978, pp. 217-219. y ábside ${ }^{\prime 30}$, pero sin hacer gala del espíritu descriptor que los extranjeros reflejaron en los libros de viaje del siglo XIX. También es cierto que este romántico inglés no conoció la obra primitiva de esta iglesia toledana, pues fueron muchas las modificaciones que se hicieron en la misma a lo largo de las centurias anteriores a su llegada a Toledo. Por ejemplo, en el año 1564 se elevó el ábside principal para alojar el nuevo retablo de Juan de Tovar $^{31}$, en 1612 los pilares de ladrillo fueron forrados con pilastras de yeso ${ }^{32}$, en 1704 se construyó un pórtico adosado al flanco sur del crucero y, por último, en 1790 se ocultó el alfarje que la cubre actualmente colocándose bóvedas encamonadas ${ }^{33}$. Es evidente que estas intervenciones desvirtuaron la imagen de la edificación primitiva, recuperada tras las restauraciones de 1958 y 1973 pero sin tener en cuenta la posible existencia de los enlucidos propios de este tipo de construcciones medievales cuya ausencia deja a la vista la estructura de ladrillo tan característica del arte mudéjar ${ }^{34}$.

También resulta interesante la referencia que Richard Ford hizo sobre la iglesia de Santo Tomé:

"A continuación visítese la iglesia contigua de San Tomé, con una torre mora

${ }^{30}$ R. FORD, Manual para viajeros por Castilla..., vol. 2, p. 80 .

${ }^{31}$ R. RAMÍREZ DE ARELLANO, Las parroquias de Toledo, facs. de la ed. de 1921, Toledo, 1997, p. 256.

${ }^{32}$ F. MARÍAS, La arquitectura del Renacimiento en Toledo (1541-1631), vol. III, Madrid, 1986, p. 30.

${ }^{33}$ C. DELGADO VALERO y T. PÉREZ HIGUERA, "Toledo islámico y mudéjar", en D. PERIS SÁNCHEZ (coord.), Arquitecturas de Toledo, vol. 1, Toledo, 1991, p. 285.

${ }^{34}$ En diferentes fotografías realizadas por Pedro Román (1878-1948) en el Toledo de finales del siglo XIX y de la primera mitad del siglo XX aún podemos apreciar los enlucidos del interior de la iglesia de Santiago del Arrabal -Pedro Román (s. a.). Detalles del Interior de la Iglesia de Santiago del Arrabal con Andamios [imagen en línea]. Junta de Comunidades de CastillaLa Mancha. Archivo de la imagen, consultado el 4 de junio de 2014. URL: http://clip.jccm.es/archivo_de_la_ imagen/es/catalogo_imagenes/grupo.cmd?texto_busqu eda $=\&$ path $=1525389 \&$ interno $=S$ 
de ladrillo. Aquí se conservó durante largo tiempo la obra maestra del Greco, El Entierro del Conde de Orgaz" ${ }^{\prime \prime}$.

Tal y como podemos apreciar en las palabras de este viajero inglés, su mirada siempre destacó la estética medieval del patrimonio visto a su paso por Toledo. Si bien, en algunas ocasiones obvió la descripción de añadidos a la estructura primitiva de estos edificios por alejarse de la manera de construir propia de la Edad Media. Por ejemplo, en la iglesia de Santo Tomé se destruyó el ábside medieval en la reforma llevada a cabo en el edificio en el siglo XVI, lo que justifica en parte que la descripción que realizó este romántico inglés se centrara únicamente en su torre, "of Moorish character"36.

El calificativo de obra "mora" al que alude Ford en su texto se deriva del hecho de que este campanario fuera siglos atrás el alminar de una antigua mezquita de $\mathrm{Tu}$ laytula. En el siglo XIV fue reconstruido por Gonzalo Ruiz de Toledo, Señor de Orgaz, pero manteniendo las características propias de este tipo de construcciones islámicas -ladrillo, adobe o tapial en la Península Ibérica como materiales destacables- para levantar el cuerpo de campanas y adaptarlo al culto cristiano $^{37}$.

Esa mirada a un arte medieval impactado por la estética andalusí también centró la descripción que Ford hizo de la iglesia de San Román, construcción donde "hay mucha obra mora -Moorish work-, con curiosos arcos y antiguas columnas $(\ldots)^{\prime \prime 38}$. Su torre no aparece descrita en su manual porque debió presentar una imagen bastante senci-

${ }^{35}$ R. FORD, Manual para viajeros por Castilla...., vol. 2, p. 88 .

${ }^{36}$ R. FORD, A handbook for travellers..., vol. 2, p. 781.

37 Hauser y Menet (1901). Iglesia de Santo Tomé. Toledo [imagen en línea]. Archivo Municipal de Toledo, consultado el 4 de junio de 2014. URL: http:// www.ayto-toledo.org/archivo/imagenes/fotos/1901/ grandes/P-3800.jpg

${ }^{38}$ R. FORD, Manual para viajeros por Castilla..., vol. 2, p. 114 . lla y diferente a la actual por estar enlucida. Es por ello que la "obra mora" que vio este inglés a su paso por San Román se corresponde con los arcos que separan las naves -de herradura califal y enmarcados en alfiz-, elementos constructivos que conoció con los estucos que se eliminaron en el siglo XX para recuperar parte de las pinturas murales apreciables en la actualidad ${ }^{39}$.

La convivencia de la estética del arte occidental europeo con las pervivencias artísticas de época islámica en el Toledo posterior a 1085 también aparece reflejada en la descripción que Richard Ford hizo de la sinagoga de Santa María la Blanca:

"La arquitectura merece ser observada con detenimiento; fíjese el visitante en las tres naves, divididas por columnas poligonales que sustentan arcos de herradura salientes de capiteles góticos híbridos; también conviene fijarse en los patronos circulares de las enjutas, las estrellas, los cuadrados y los arcos moros angrelados." ${ }^{40}$

O en el convento de San Juan de la Penitencia:

"Y que nadie deje de visitar San Juan de la Penitencia, fundado por Ximénez en 1511, porque la capilla es del más rico gótico florido, con un atisbo del estilo moro (...). El techo de artesonado, con esquinas descendentes en forma de panal e intrincada obra romboide es digno de la Alhambra" ${ }^{\prime 1}$.

Entre otras muchas alusiones a este tipo de construcciones medievales recogidas por el inglés Richard Ford en su A handbook

39 Del estado del interior de la iglesia antes de eliminar esos enlucidos se conservan algunas fotografías en el Fondo Fotográfico Casa Rodríguez (s. a.). Iglesia de San Román. Interior [imagen en línea]. Junta de Comunidades de Castilla-La Mancha. Archivo de la imagen, consultado el 4 de junio de 2014. URL: http://clip.jccm.es/archivo_de_la_imagen/es/catalogo_ imagenes/grupo.cmd?texto_busqueda=\&path=1522936 \&interno $=S$

${ }^{40}$ R. FORD, Manual para viajeros por Castilla..., vol. 2, pp. $84-85$.

${ }^{41}$ Ibídem, p. 114. 
for travellers in Spain and readers at home no debemos olvidar la descripción de la Sala Capitular de la catedral, precedida de una antesala "very Moorish"42. Esta estancia, obra de Enrique Egás y Pedro de Gumiel (1504-1512) y catalogada dentro del denominado "estilo Cisneros", es una muestra del uso de elementos góticos, renacentistas e hispanomusulmanes en una misma construcción. Esta última influencia ha permitido a algunos de historiadores del arte hablar de la presencia de la estética mudéjar en esta sala catedralicia ${ }^{43}$.

El texto de este viajero inglés, escrito con anterioridad al discurso pronunciado por Amador de los Ríos en 1859, es una muestra de que estos edificios debían ser pequeños y sencillos oratorios poco llamativos para los visitantes de la ciudad. En la mayoría de los casos, la imagen primitiva de estas construcciones nada tenía que ver con la que presentaron a los viajeros algunas centurias después, sobre todo por esa tendencia restauradora de los siglos XIX y XX partidaria de eliminar los enlucidos originales para dejar a la vista la estructura de ladrillo, mampostería, adobe o piedra.

Es probable, por tanto, que el carácter popular de este patrimonio medieval pudiera ser la causa de que las descripciones sobre el mismo recogidas en la literatura de viajes no atiendan a ese carácter de "turista descriptor y daguerrotipo literario" 44 que los extranjeros pusieron de manifiesto cuando se enfrentaron a obras como la catedral o San Juan de los Reyes. Pero además, las palabras de Ford evidencian que estamos ante edificios que siguen las pautas de la arquitectura medieval, románica o gótica, con influencias evidentes de un arte andalusí que marcó la historia de Toledo desde los primeros años del siglo VIII.

${ }^{42}$ R. FORD, A handbook for travellers..., vol. 2, p. 792.

${ }^{43}$ T. PÉREZ HIGUERA, "Toledo gótico", en A. DE LA MORENA BARTOLOMÉ (coord.), Castilla la Mancha. Toledo, Guadalajara y Madrid, Madrid, 1998, p. 30.

${ }^{44}$ T. GAUTIER, Viaje a España, Madrid, 1998, p. 195.
Esta última opinión creo que se apoya de manera más firme si utilizamos un texto como el Voyage en Espagne del ilustrador Gustave Doré y de Charles Davillier, viajeros franceses que pocos años después de 1859 presentaron a los lectores de sus memorias un "style d'architecture auquel on a donné en Espagne le nom de estilo mudéjar" ${ }^{45}$. Davillier, autor del texto escrito que acompañaba los grabados de Doré y que recorrió la Península a partir del año 1862, aludió de manera clara a una arquitectura románica u ojival en la que es frecuente encontrar ornamentos hispanomusulmanes:

"Durante la Edad Media (...) fueron empleados en Castilla, en Aragón y, en otras partes de España alarifes moros sometidos a la dominación cristiana y a los que se da el nombre de mudéjares (...). Cuando eran empleados como arquitectos o como escultores ornamentistas, los alarifes mudéjares trabajaban, ya en las nuevas construcciones, ya en edificios que restauraban, sin respetar su estilo. Así se ve con frecuencia un edificio de estilo románico u ojival que tiene ciertos detalles completamente moros ${ }^{\prime \prime 4}$.

El hecho de que las iglesias y sinagogas medievales de Toledo participen de las características de una arquitectura románica u "ojival" impactada por el arte andalusí es la causa de que las descripciones de Davillier no muestren enormes diferencias respecto a las que realizó Ford en los años treinta del siglo XIX. Tanto es así que este viajero francés continuó aludiendo a ese "style moresque" repetido por viajeros anteriores como Ford -"Moorish character", en el caso del ingléspara describir la estética de muchas de las obras catalogadas como mudéjares.

Los rasgos propios de esa arquitectura "mora" fueron los que Charles Davillier destacó en edificios como el de Santa María la Blanca, "du style qu'on a désigné en Es342 .

${ }^{45}$ G. DORÉ y CH. DAVILLIER, “Voyage en...”, p.

${ }^{46}$ G. DORÉ y CH. DAVILLIER, Viaje por..., vol. 2, p. 138 
pagne sous le nom de estilo del Califato, et son architecture ne manque pas d'analogie avec celle de la mosquée de Cordoue" ${ }^{47}$. La principal causa de la comparación de este edificio toledano con la mezquita cordobesa reside en el uso de elementos estructurales en la sinagoga heredados de la manera de construir andalusí, sobre todo en los arcos que separan las naves ${ }^{48}$. Si bien, hemos de tener en cuenta que los estudiosos de esta sinagoga han fijado la cronología de su construcción en el siglo $\mathrm{XIV}^{49}$, mientras que el estilo califal mencionado por Davillier se desarrolló varios siglos antes.

Si avanzamos con la lectura y el análisis del texto de Davillier, encontramos una apreciación semejante a la que acabamos de ver para Santa María la Blanca cuando se enfrentó a la obra de la sinagoga del Tránsito ${ }^{50}$ : "le style des monuments rapelle beacoup celui des salles de l'Alhambra" ${ }^{51}$.

La vinculación de la arquitectura de estas sinagogas toledanas con el "estilo moro" es causa, además del uso del arco de herradura en su construcción, de la influen338.

${ }^{47}$ G. DORÉ y CH. DAVILLIER, “Voyage en...", p.

48 Véanse fotografías como la de Pedro Román, conservada en Fondo Fotográfico Casa Rodríguez (s. a.), Arcos, Detalle de los Capiteles y Frisos Mudéjares del Museo Sinagoga Santa Maria la Blanca [imagen en línea]. Junta de Comunidades de Castilla-La Mancha. Archivo de la imagen, consultado el 6 de junio de 2014. URL: http://clip.jccm.es/archivo_de_la_imagen/es/catalogo_ imagenes/grupo.cmd?path=1525348\&interno $=S$

49 J. C. RUIZ SOUZA, “Sinagogas sefardíes monumentales en el contexto de la arquitectura medieval hispana", en I. BANGO GARCÍA (coord.), Memoria de Sefarad. Catálogo de la Exposición, Madrid, 2002, p. 230.

50 Véase la fotografía conservada en el Fondo Fotográfico Casa Rodríguez (s. a.). Sinagoga del Tránsito. Interior [imagen en línea]. Junta de Comunidades de Castilla-La Mancha. Archivo de la imagen, consultado el 6 de junio de 2014. URL: http://clip.jccm.es/archivo_de_ la_imagen/es/catalogo_imagenes/grupo.cmd?texto_bu squeda $=\&$ path $=1522214 \&$ interno $=S$ 338

${ }^{51}$ G. DORÉ y CH. DAVILLIER, "Voyage en...", p. cia que se detecta de la decoración nazarí y meriní del siglo XIV. Estamos, de esta manera, ante una muestra de esa diversidad artística que caracterizó al Toledo bajomedieval ya advertida por el profesor Ruiz Souza, pues en los mismos años se están construyendo "edificios muy diferentes entre sí como la sinagoga del Tránsito (...), las naves góticas de la catedral o la capilla de San Blas $(\ldots)^{\prime \prime 52}$.

Continuando con el análisis del impacto del estilo de Amador de los Ríos en la literatura de viajes, hemos de señalar que Davillier sólo calificó como "mudéjares" el Salón de la Mesa y el Taller del Moro. Este hecho nos lleva a valorar la influencia de los textos que le ayudaron a definir las características de este tipo de construcciones. En este sentido, es probable que este viajero francés conociera el discurso leído por el propio Amador de los Ríos, ya que estamos ante una fuente cercana en el tiempo a su paso por España y en la que se ubican estos dos edificios dentro del "estilo mudéjar"53. No obstante, no se olvidó de ese calificativo de "moresques" atribuido por los viajeros extranjeros a numerosos edificios toledanos:

“Le Salón de la casa de la Mesa et le Taller del Moro sont ensuite les plus curieux édifices moresques de Tolède: l'un et l'autre appartiennent au style d'architecture auquel on a donné en Espagne le nom de estilo Mudéjar"54.

Por otro lado, cabe señalar que algunas traducciones al español de las memorias de estos extranjeros han asimilado el calificativo de "moresque" o "moorish", utilizado por los viajeros para describir una arquitectura medieval que participó de la forma de construir andalusí, con el término "mudéjar". Este hecho puede conducir a interpretaciones erróneas sobre la valoración y

${ }^{52}$ J. C. RUIZ SOUZA, “Construcción y búsqueda de un estilo...", p. 198.

${ }^{53}$ J. AMADOR DE LOS RÍOS, Op.cit., pp. 24-25.

${ }^{54}$ G. DORÉ y CH. DAVILLIER, “Voyage en...", p. 342 
presencia del estilo de Amador de los Ríos en la literatura de viajes. Sirva de ejemplo la descripción que Davillier realizó de la Sala Capitular de la catedral de Toledo ${ }^{55}$. En su texto original podemos leer:

"La Sala capitular de la cathédrale de Tolède est, sans contredit, la plus belle et la plus intéressante qui existe en Espagne; la pièce d'entrée ou antesala, dont la décoration dans le style moresque est merveilleusement conservée, nous rappela beaucoup les salles de l'Alhambra; le plafond surtout, du genre qu'on appelle en Espagne artesonado, est tout resplendissant d'or et d'azur (... $)^{\prime \prime 56}$.

Por contra, algunas traducciones de su texto al español señalan:

"La Sala Capitular de la catedral de Toledo es, sin disputa, la más hermosa y la más interesante que existe en España. La antesala, cuya decoración en estilo mudéjar está maravillosamente bien conservada, nos recordó mucho a las salas de la Alhambra. El techo sobre todo, que es lo que se llama en España un artesonado, resplandece de oro y de azul" ${ }^{\prime \prime}$.

Sobre el resto de iglesias medievales de Toledo, Davillier, al igual que la mayor parte de los viajeros que visitaron la antigua capital visigoda, no dio ninguna noticia de interés. Mientras casi todos los extranjeros recogieron en sus memorias numerosas referencias a la catedral, al alcázar o al monasterio de San Juan de los Reyes como obras representativas de la grandeza del Toledo medieval, las modestas iglesias de barrio catalogadas como mudéjares se presentaron a

55 Fondo Fotográfico Casa Rodríguez (s. a.). Portada en Yesería Mudéjar de la Sala Capitular. Obra de Blandino Bonifacio (S. XVI) [imagen en línea]. Junta de Comunidades de Castilla-La Mancha. Archivo de la imagen, consultado el 6 de junio de 2014. URL: http://clip.jccm.es/archivo_de_la_imagen/es/catalogo_ imagenes/grupo.cmd?path=1526135\&interno $=S$

${ }^{56}$ G. DORÉ y CH. DAVILLIER, “Voyage en...”, pp. 328-330.

${ }^{57}$ G. DORÉ y CH. DAVILLIER, Viaje por..., vol. 2, p. 121. la mirada de estos viajeros como construcciones bastante sencillas que poco tenían que destacar.

El carácter popular de este tipo de arquitectura medieval me lleva a poner en tela de juicio la posibilidad de que estas construcciones fueran objeto de olvido y el desinterés de muchos viajeros -sobre todo con anterioridad a 1859- por encontrarse "ante algo que se sale de sus esquemas" 58 . Más bien, hemos de plantearnos que los visitantes de Toledo no se sintieron atraídos por una arquitectura que quedó eclipsada ante la grandeza de obras como catedral o San Juan de los Reyes. Además, y vuelvo a insistir en este sentido, es evidente que la imagen primitiva de estas iglesias medievales nada tenía que ver con la que muestran en la actualidad -y en muchos casos ya en las últimas décadas del siglo XIX- por haber hecho desaparecer esos enlucidos que ocultaban las fábricas de ladrillo o adobe apreciables a día de hoy.

Vistas las aportaciones de los textos de Ford y Davillier, cabe destacar a modo de conclusión que el hecho de que las memorias de ambos viajeros sean tan parecidas a pesar de su distancia en el tiempo es otra muestra de lo confuso que resulta definir de una manera clara el mudéjar como categoría estilística. Si tenemos en cuenta el contexto en el que surgió "El estilo mudéjar en arquitectura", es evidente que la formulación de Amador de los Ríos es la consecuencia de la búsqueda de una expresión artística hispánica en el contexto nacionalista propio del siglo XIX. No hemos de olvidar que el movimiento romántico español se preocupó por revalorizar nuestro pasado medieval, sentimiento que se vio materializado en publicaciones periódicas dedicadas al estudio del patrimonio nacional como el Semanario

58 V. GIJÓN JIMÉNEZ, “El arte mudéjar de Toledo a través de la literatura de viajes. De Münzer a Demolder", en CENTRO DE ESTUDIOS MUDÉJARES (ed.), Actas del XI Simposio Internacional de Mudejarismo, celebrado en Teruel del 18 al 20 de septiembre de 2008, Teruel, 2009, p. 526. 
Pintoresco Español (1836-1857) $)^{59}$ o el Boletín Español de Arquitectura (1846) ${ }^{60}$, o en colecciones como Recuerdos y bellezas de España $(1839-1872)^{61}$. Para el caso de Toledo, podemos destacar trabajos monográficos como Toledo pintoresca, del propio José Amador de los Ríos ${ }^{62}$, el Toledo en la mano, texto del cronista Sixto Ramón Parro ${ }^{63}$, o la Historia de los templos de España, obra en la que Gustavo Adolfo Bécquer describió los edificios religiosos toledanos ${ }^{64}$.

Además, y centrando nuestra mirada en las apreciaciones de los viajeros referidas a las características formales de estos edificios medievales, hemos de señalar que las construcciones catalogadas como mudéjares se caracterizan por el uso de formas arquitectónicas propias de la tradición medieval románica o gótica -ojival en palabras de Davillier- en las que se detecta una más que justificada influencia del arte andalusí. Esta misma pervivencia de formas hispanomu-

59 Este semanario fue fundado por Mesonero Romanos en 1836 y publicó hasta 1857 trabajos organizados en diferentes secciones fijas (España pintoresca, Bellas Artes, Crítica literaria, etc.) Véase al respecto el índice de publicaciones periódicas realizado por J. SIMÓN DÍAZ, Semanario pintoresco español (Madrid, 1836-1857), Madrid, 1946.

${ }^{60}$ Dirigido por José Amador de los Ríos y Antonio de Zabaleta, este boletín fue la primera edición periódica en España dedicada exclusivamente a estudios sobre arquitectura. Para profundizar en el conocimiento de esta publicación véase J. E. GARCÍA MELERO, Literatura española sobre artes plásticas. Bibliografía aparecida en España durante el siglo XIX, vol. 2, Madrid, 2002, pp. 176-177.

${ }^{61}$ En esta colección el litógrafo Francisco Javier Parcerisa y escritores como José María Quadrado, Francisco Pi i Margall o Pedro de Madrazo, entre otros, plasmaron ese interés por dar a conocer el patrimonio monumental español en el siglo XIX. Véase al respecto J. Ma ARIÑO COLÁS, Recuerdos y bellezas de España: ideología y estética, Zaragoza, 2007.

62 J. AMADOR DE LOS RÍOS, Toledo pintoresca, o descripción de sus más célebres monumentos, facs. de la ed. 1845, Toledo, 1989.

${ }^{63}$ S. RAMÓN PARRO, Op. cit.

${ }^{64}$ G. A. BÉCQUER, Historia de los templos de España: Toledo, Toledo, 2005 (reimpr.). sulmanas también es común encontrarla en estructuras medievales que no se etiquetan como mudéjares. Sirva de ejemplo para el caso de Toledo el uso de arcos polilobulados de clara inspiración andalusí en construcciones góticas como la girola de la catedral o de elementos decorativos como los mocárabes en el interior de la iglesia del monasterio de San Juan de los Reyes. Ejemplos como estos han llevado a plantear si el abundante uso del ladrillo en estructuras que originalmente se estucaron, la utilización del adobe o la mampostería, el uso de armaduras de madera en las techumbres ${ }^{65} \mathrm{o}$ el hecho de que un musulmán fuese el artífice de una obra son elementos suficientes para fundamentar la viabilidad de usar el término "mudéjar" como categoría estilística ${ }^{66}$.

Por último, y para justificar el protagonismo que estas iglesias medievales tuvieron para la mirada de los viajeros extranjeros de la segunda mitad del siglo XIX, cabe destacar que el estilo de Amador de los Ríos se está usando de un tiempo a esta parte

“[...] para revalorizar construcciones que sencillamente son de carácter popular y tradicional en muchos casos, y para reivindicar una más que dudosa convivencia en-

\footnotetext{
65 Sobre la carpintería de armar véanse ejemplos de arquitectura civil como el del desaparecido Palacio Real de León, un edificio que se construyó siguiendo la tradición del siglo XIV y que se mostró como ejemplo del intercambio de propuestas entre las culturas cristiana e islámica en la Edad Media (J. GARCÍA NISTAL, "La carpintería de armar en el antiguo Palacio Real de León”, De Arte, 2, 2003, pp. 127-143).

66 Sobre la autoría de las obras consideradas mudéjares ya advertía Pedro de Madrazo en 1888: "[...] ¿tenemos por ventura la seguridad de que todo lo que se califica hoy de mudéjar es producto de manos mudéjares? [...] porque así como hubo en el siglo de San Fernando un Pero Pérez, arquitecto cristiano, que para trazar la galería de la capilla mayor de la Catedral de Toledo se inspiró en las construcciones de carácter mauritano, hubo en el siglo XVI un López de Arenas, seguido de una falange de imitadores tan peritos en el modo de labrar los artesonados de lacería y ensambladura, como los mismos carpinteros moros" (P. DE MADRAZO, Op. cit., p. 263).
} 
tre las tres culturas (cristiana, musulmana y hebrea) presentes en la España medieval" ${ }^{\prime \prime 7}$.

En definitiva, y a modo de cierre de todo lo tratado, hemos de destacar que las descripciones de algunos extranjeros llegados a España en el siglo del Romanticismo -caso de Richard Ford y Charles Davillierdemuestran lo confuso que ha resultado desde 1859 dar una definición precisa del estilo mudéjar. Viajeros que ya conocían el discurso de De los Ríos, como es el caso del francés, hacen referencia a un carácter "moro" al enfrentarse a la descripción de construcciones que en ocasiones incluyen bajo un "estilo románico u ojival"68. En consecuencia, y teniendo como referencia aportaciones de este tipo, considero oportuno colocar esta arquitectura bajo el calificativo de medieval, románica o gótica en esencia, a la hora de estudiarla a través de la literatura de viajes. Si bien, y atendiendo a ese recuerdo a la estética del arte andalusí tan presente en las memorias de los extranjeros llegados a Toledo en la segunda mitad del siglo XIX, cabe valorar estas construcciones como una muestra más de la influencia ejercida por la cultura islámica en la Península Ibérica en todos los ámbitos del saber.
${ }^{67}$ J. C. RUIZ SOUZA, “Construcción y búsqueda de un estilo...", p. 183.
${ }^{68}$ G. DORÉ y CH. DAVILLIER, Viaje por..., vol. 2, p. 138. 